\title{
THE EFFECT OF TEMPERATURE ON THE POLYMORPHISM OF CYANOGENESIS IN LOTUS CORNICULATUS L.
}

\author{
W. M. ELLIS, R. J. KEYMER and DAVID A. JONES \\ Unit of Genetics, The University, Hull HU6 7RX
}

Received 1.xi.76

\begin{abstract}
Summary
Genotype $\times$ environment interactions associated with temperature were shown to occur in populations of $L$. corniculatus. The effects were related to the genetic structure of the populations. We were able to show, however, that cold temperature does not act directly as a selective agent on the polymorphism of cyanogenesis in L. corniculatus.
\end{abstract}

\section{INTRODUCTION}

Gyanogenesis has been studied in populations of both Lotus corniculatus $\mathrm{L}$. and Trifolium repens $\mathrm{L}$. and it appears that the polymorphism in these species is similar in many respects (Dawson, 1941; Corkill, 1942; Atwood and Sullivan, 1943; Bansal, 1966; Foulds and Grime, 1972; CrawfordSidebotham, 1972b). One difference is that temperature has been nominated as one of the selective agents acting on the polymorphism in $T$. repens, because the cyanogenic phenotype appears to be an advantage at high temperatures and the acyanogenic phenotype at low temperatures (Daday, 1965). The frequency distributions of the phenotypes by latitude (Daday, 1954a) and by altitude (Daday, 1954b; de Araújo, 1976) support this hypothesis. Field tests of populations of $L$. corniculatus in Europe, however, do not give a distribution parallel to that of $T$. repens (Jones, 1977). Furthermore, diurnal and seasonal variation in the expression of the cyanogenic phenotype has been observed in both species (Armstrong, et al., 1913; Askew, 1933; de Waal, 1942; Corkill, 1942; Jones, 1962) and it may be that this developmental flexibility (Westerman and Lawrence, 1970) for cyanogenesis is associated with temperature. The work reported here estimates the effect of temperature on the polymorphism of cyanogenesis in L. corniculatus.

\section{Materials and methods}

The effect of temperature can be assessed by measuring seasonal changes in the frequency of cyanogenic plants in a natural population and in glasshouse stock plants and by growing plants in controlled environments. The method of testing leaves for cyanogenesis has been given in detail elsewhere (Jones, 1966). Only plants scoring ++ for the presence of cyano-glucosides with $\beta$-glucosidase are cyanogenic. In field tests three phenotypes can be distinguished,,+++- and - ?. Laboratory tests can distinguish the fourth phenotype, - - from -+ , with the addition of $0.5 \mathrm{ml} \mathrm{l} \mu \mathrm{M}$ linamarin to a replicate tube. The tests were standardised as far as possible: young shoots with two or three leaves were used and the tests were always set up in the morning and scored after 24 hours' incubation on the laboratory bench. 


\section{(i) Field test}

The natural population selected for study was at Wharram Quarry, N. Yorkshire. At monthly intervals over a period of more than a year, plants were sampled at random and tested for cyanogenesis. The sample size was always between 100 and 200, and the distance between the plants sampled was more than $1 \mathrm{~m}$. Data of the mean monthly maximum and minimum temperatures in the area were collected from High Mowthorpe Experimental Husbandry Farm, about $3 \mathrm{~km}$ north-east of the quarry. Regression analysis of the frequency of cyanogenic plants against temperature was carried out.

\section{(ii) Glasshouse tests}

Stock plants were taken as cuttings from two natural populations, 27 from Wharram Quarry and 140 from Porthdafarch, Anglesey. The Wharram population appears to be polymorphic for the enzyme only, but the Anglesey population contains all four phenotypes and the stock plants included them all. Half of the Anglesey cuttings were taken from the cliff where 20 per cent of the plants were cyanogenic and the other half were collected farther inland where 80 per cent of the plants were cyanogenic (Ellis et al., 1977b). These plants were grown in John Innes No. 2 compost in $12.5 \mathrm{~cm}$ pots in the glasshouse. They were tested at 2-monthly intervals over a period of 18 months and the maximum and minimum temperatures in the glasshouses were recorded daily. Regression analyses of the frequency of the phenotypes against temperature were carried out.

\section{(iii) Controlled temperature experiment}

From the routine glasshouse testing of the Anglesey stock plants, plants with stable and unstable phenotypic expression were isolated. There are five possible categories of instability, $++\vec{\rightleftharpoons}-,++\rightleftharpoons+-,++\rightleftharpoons-$ ,$++-\rightleftharpoons--$ and $-+\rightleftharpoons--$. The first category includes all plants which are unstable both for the glucoside and for the enzyme phenotype and will necessarily include (on transition from $++\rightleftharpoons--$ ) +- and/or -+ . Hence, the sixth possibility $+-\rightleftharpoons-+$, is part of the $++\rightleftharpoons--$ category. Three plants stable for the,+++- and -+ phenotypes were used as controls, and two plants in each of the unstable categories were used in the experiment. Six ramets of each plant were propagated in the mist unit and potted in $9 \mathrm{~cm}$ pots after 6 weeks. They were then grown under lights in a warm glasshouse (minimum temperature $15^{\circ} \mathrm{C}$ ) for a further 10 weeks and transferred, at 16 weeks, to a controlled environment cabinet, where they were arranged in two randomised blocks. Day length, relative humidity and light were held constant at 14 hours, 80 per cent and 150 to 250 micro-einsteins $\mathrm{M}^{-2}$ and $\sec ^{-1}$ respectively, so that the only variable was temperature. The plants were tested for cyanogenesis after I or 2 weeks in each temperature regime. The day and night temperatures and the age of the plants at the time of testing are shown in table 3. Because light becomes limiting in long-term growth cabinet experiments, there being less than half normal daylight available, the plants were placed outside (mean maximum temperature $36^{\circ} \mathrm{C}$, mean minimum $11^{\circ} \mathrm{C}$ ) for 2 weeks' recuperation and tested to determine whether their phenotypic expression would return to normal July levels. They were then replaced in the growth cabinet for the two final tests. 


\section{(iv) Cold stress experiments}

Two series of experiments were carried out on cloned stock plants from the two populations. During the course of each experiment, all the plants were tested for cyanogenesis, to be sure that the phenotypes being tested were expressed.

Series 1, Wharram. Because there appeared to be only two phenotypes in this population, ++ and +- , the experiments were designed using eight plants per phenotype and three ramets per plant, the plants being randomly arranged after they were potted. Four weeks after propagating in a mist unit in the glasshouse, the plants were potted in $8 \mathrm{~cm}$ peat pots, grown for 2 weeks under lights in a warm glasshouse, hardened for 4 days in a cool glasshouse with no supplementary lighting and then transferred to a controlled environment cabinet with a day length of 12 hours and temperature of $7^{\circ} \mathrm{C}$. Each experiment lasted 1 week and throughout the week the night temperature was held constant, for example in experiment 1 the night temperature was $-1^{\circ} \mathrm{G}$. Six further experiments were carried out with night temperatures of $-2^{\circ} \mathrm{C},-3^{\circ} \mathrm{C},-3.5^{\circ} \mathrm{C},-4^{\circ} \mathrm{C},-5^{\circ} \mathrm{C}$ and $-6^{\circ} \mathrm{C}$. A total of 336 plants was used in these seven experiments. The plants were scored for their subsequent recovery in the cool glasshouse.

Series 2, Anglesey. Only plants known to be stable for the expression of the four phenotypes were used, three plants per phenotype and four ramets per plant. The plants were grown in the same way as the Wharram plants but were given 6 weeks under lights in a warm glasshouse before being hardened and only four experiments were carried out with night temperatures of $-2^{\circ} \mathrm{C}$ to $-5^{\circ} \mathrm{C}$ inclusive.

\section{Results AND Discussion}

\section{(i) Field test}

The frequency of cyanogenic plants scored in the Wharram population ranged from 60 to 82 per cent, there being only two phenotypes, ++ and +- , in all but two samples. Only in the winter of 1975-76 were - ? plants scored, 15 per cent in February and 16 per cent in March. Regressions of the frequency of ++ plants against mean monthly minimum and maximum temperatures recorded at High Mowthorpe for the month of the test and the previous month were not significant (table 1). Thus although there is significant variation in phenotypic expression it appears to be unrelated to temperature. It is possible that the variation is due to sampling error, because $L$. corniculatus plants are not distributed at random in Wharram Quarry (Usher, 1975) and a greater difference may be expected between two random samples of such a population than between systematic area samples (Jones, 1977).

Our interpretation of these results depends on two assumptions and on other results to be presented in the next section of this paper. One assumption is that the - ? plants were not expressing the +- phenotype in the second winter because of their developmental flexibility in response to the generally low temperatures and frequent frosts from December onwards, whereas the previous winter had been very mild until Easter. The other is that the recessive non-glucoside phenotype is absent from this population. 
TABLE 1

Analyses of variance of regressions for the frequency of cyanogenic plants (in angles) at Wharram Quarry against mean maximum and minimum temperatures, recorded in the month of sampling and the previous month at High Mowethorpe

\begin{tabular}{clrrr} 
Sampling month & \multicolumn{1}{c}{ Source } & d.f. & MS & \\
Maximum $\mathrm{T}^{\circ} \mathrm{C}$ & $\begin{array}{l}\text { Regression } \\
\text { Residual }\end{array}$ & 1 & 25.92 & n.s. \\
Minimum $\mathrm{T}^{\circ} \mathrm{C}$ & $\begin{array}{l}\text { Regression } \\
\text { Residual }\end{array}$ & 16 & $32 \cdot 74$ & n.s. \\
& & $15 \cdot 34$ & \\
Previous month & & & & \\
Maximum $\mathrm{T}^{\circ} \mathrm{C}$ & Regression & 1 & $12 \cdot 19$ & n.s \\
& Residual & 16 & $16 \cdot 60$ & \\
Minimum $\mathrm{T}^{\circ} \mathrm{C}$ & Regression & 1 & 6.92 & n.s. \\
& Residual & 16 & 16.93 &
\end{tabular}

Note, however, that if we assume that the glucoside locus shows tetrasomic inheritance (Dawson, 1941), a recessive allele frequency of 27 per cent could be missed in a sample of 200 plants. If these assumptions are correct, then we may consider that this population is monomorphic for the glucoside implying that most plants are quadruplex or triplex for the dominant cyano-glucoside allele. It follows that stability of phenotypic expression for the cyano-glucoside may be associated with homozygosity and higher order heterozygosity.

\section{(ii) Glasshouse tests}

The Wharram stock plants were all stable in phenotypic expression. This demonstrates the reliability of the test for cyanogenesis in this context and validates the use of the test for recognising individuals with unstable phenotypic expression. Furthermore, there is good evidence that the test does distinguish between the phenotypic classes upon which selection can

TABLE 2

Analyses of variance of regressions for the per cent expression (transformed to angles) of the cyanoglucoside and the $\beta$-glucosidase phenotypes in the Anglesey stock plants against maximum and minimum glasshouse temperatures

\begin{tabular}{|c|c|c|c|c|}
\hline & Source & d.f. & MS & \\
\hline \multicolumn{5}{|l|}{ Cyanoglucoside } \\
\hline \multirow[t]{2}{*}{ Maximum $\mathrm{T}^{\circ} \mathrm{C}$} & Regression & 1 & $101 \cdot 37$ & n.s. \\
\hline & Residual & 6 & $98 \cdot 02$ & \\
\hline \multirow[t]{2}{*}{ Minimum $\mathrm{T}^{\circ} \mathrm{C}$} & Regression & 1 & $348 \cdot 38^{*}$ & \\
\hline & Residual & 6 & $56 \cdot 85$ & \\
\hline \multicolumn{5}{|l|}{$\beta$-glucosidase } \\
\hline \multirow[t]{2}{*}{ Maximum $\mathrm{T}^{\circ} \mathrm{C}$} & Regression & 1 & $41 \cdot 64 * *$ & \\
\hline & Residual & 6 & $3 \cdot 26$ & \\
\hline \multirow[t]{2}{*}{ Minimum $\mathbf{T}^{\circ} \mathrm{C}$} & Regression & 1 & $3 \cdot 01$ & n.s. \\
\hline & Residual & 6 & $9 \cdot 70$ & \\
\hline
\end{tabular}

* Significant at 5 per cent. ** Significant at 1 per cent. 
Table 3

Cyanogenesis scores within clones at different temperatures

Age at test in weeks

Day/night temperature

\begin{tabular}{cccccccc}
\hline 18 & 20 & 21 & 22 & 24 & 26 & 29 & 30 \\
$15^{\circ} \mathrm{C}$ & $10^{\circ} \mathrm{C}$ & $10 / 6^{\circ} \mathrm{C}$ & $10 / 5^{\circ} \mathrm{C}$ & $8 / 4^{\circ} \mathrm{C}$ & $36 / 11^{\circ} \mathrm{C}$ & $20 / 15^{\circ} \mathrm{C}$ & $5 / 5^{\circ} \mathrm{C}$
\end{tabular}

Unstable

phenotype
category

$++\rightleftharpoons+$

$++\rightleftharpoons-$

$+-\rightleftharpoons-$

$-+\rightleftharpoons--$

Totals

\section{Clone no.}

C28

D7

$\begin{array}{ll}++ & ++ \\ ++ & ++ \\ ++ & +- \\ +- & +- \\ ++ & ++ \\ +- & ++\end{array}$

+-
++
++
++
++
+-

+-
++
++
+-
+-
+-

$+-$

$+-$

$++$

$+-$

$+-$

$++\quad+$

$+-$

$+-t$

$++t$

$++\quad+$

++
++

++
+-

$\begin{array}{ll}+- & ++ \\ ++ & ++\end{array}$

+-
++

$++$

$+$

$+-$

$+$

$+-$

$+-$

$++$

$++$

$++$

$++$

+-
+-

A22

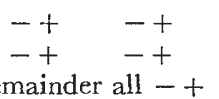

A7

$$
-+\quad-+
$$

$-+$

$-+$

-+
-+

$-+$

$-+$

$+-$

$+-$

$+$

$++$

+-
+-

$++$

$++$

$+$

$++$

++
++

$+-\quad+-$

$+-\quad+$

$+-\quad+$

$+-\quad-$

$+-\quad+$

$+-\quad+$

$+-\quad+$

$+-\quad+-$

$+-\quad+-$

$+-+$

$++\quad+-$

$+++-$

$--\quad-+\quad-+$

$-+\quad++\quad-+$

$++$

-+
-+

$-$

-+
-+
+

$+-+$

$--\quad-$

$++\quad+$

$++$

$-+\quad-+$

$-+$

-+
-+

$-+$

$-+$

$-+\quad++\quad-+$

$++-+\quad-+$

$++\quad-+\quad-+$

$-+\cdots--$

$++-\infty$

$\begin{array}{lllllllll}-+ & + & + & + & + & - & - & - & +\end{array}$

A3

$++$

$+-$

$++$

$++$

$+t$
$+t$

$--$

$-$

$\begin{array}{llll}++ & ++ & +- & ++ \\ ++ & ++ & ++ & ++\end{array}$

$++t+$

$++$

++
+-

$++$

-+
++

++
-+

$-++$

$-+\quad++\quad-+$

$--1$

$-$

$++$

$+-$

$+-\quad+-$

$-+\quad+-$

A35

$\begin{array}{ccc}- & - & ++\end{array}$

$+$

$--$

$+-$

$+$

$+-$

$+-$

$++$

$+-$

$+-$

$++$

$++--$

$+-+$

$+-$

$+$

$--$

$++$

$+-$

$+-$

$-$

$++$

$+-\quad+$

$++$

$+-$

$+-$

$++$

$-+\quad+$

$+-$

$+-+$

$\begin{array}{ll}+- & +\cdots \\ +- & -+\end{array}$

A6

$$
+-
$$$$
-
$$

$--$

$--$

$-$

$+-\quad+-$

$+$

$+-$

$+2$

江

$$
+-
$$

+

$-+$

$--\quad+-$

A13

$+-$

$$
+-
$$

remainder all +-

A28

remainder all -

A I

$$
\text { remainder all - }-
$$

G+

34

34
27

36

25

33

26

29

23

27

33

26

24

$38 / 3-\mathrm{E}$ 
be shown to act (Jones, 1966). There was considerable variation of expression in the Anglesey stock plants and this could be related to temperature. Regression of the per cent expression of the cyano-glucoside phenotype against mean monthly minimum temperature and the per cent expression of the $\beta$-glucosidase phenotype against mean monthly maximum temperature were both significant (table 2), showing that at low temperatures some plants reduce their cyano-glucoside content and that at high temperatures more plants show enzyme activity.

Because all four phenotypes have been found in the Anglesey population, we can assume that heterozygotes for both the glucoside and the enzyme occur. If the stability of the Wharram plants is due to their postulated quadruplex or triplex allele dosage, then the stable ++ and +- Anglesey plants could also be quadruplex or triplex for the glucoside and the unstable plants may be duplex or simplex. This poses the possibility that lower order heterozygotes rnay show developmental flexibility.

\section{(iii) Controlled temperature experiment}

Throughout this experiment the control plants remained stable and were clearly distinct from the unstable plants. In these latter the variation within clones was as great as between clones and no clear-cut temperature threshold could be seen (table 3 ). However, the total numbers of phenotypes expressed did show a decrease in both the cyano-glucoside and the enzyme, and although regressions of these numbers against temperature were not significant $(0 \cdot 1>P>0 \cdot 05)$ it is possible that the plants respond to changes in temperature rather than absolute values. It is clear, therefore, that we cannot distinguish between developmental flexibility or developmental instability in this situation, but the tendency for the unstable plants, overall, to respond to temperatures in the same way does suggest the former.

The significance of these results is that our selected unstable plants did show phenotypic instability in controlled environments in which temperature was the only variable, whereas the stable plants did not.

The occurrence of variation within clones for the phenotypic expression of cyanogenesis shows that we cannot assume that replicates of a plant will always express the same phenotype in the same environment. Inequalities between propagules of $L$. corniculatus at cloning have been shown to affect their subsequent morphology (Ostazeski and Henson, 1965) and it seems that micro-environmental variation at the time of cloning could cause physiological variation between ramets. Similar effects have been found with Mimulus guttatus Fisch. (Libby and Jund, 1962) and Lolium perenne L. (Breese, et al., 1965).

\section{(iv) Cold stress experiments}

The results were expressed as the total number of survivors of each phenotype plotted against temperature (fig. l). The variation of temperature within the cabinet was probably at least $\pm 1^{\circ} \mathrm{C}$ and because the variation within clones may have been caused by position effects the replicates were treated as individuals in the results. From fig. 1 it can be seen that there is little difference between the populations or the phenotypes, about half the plants dying at $-4^{\circ} \mathrm{C}$. 
SERIES 1

WHARRAM QUARRY

$7(\mathrm{~N}=48: 2 \mathrm{Ph} \times 8 \mathrm{P} 1 \times 3 \mathrm{Ra})$

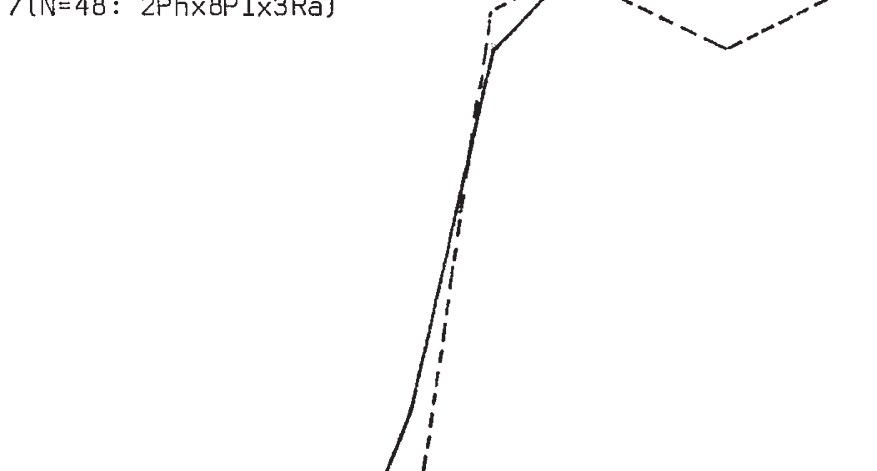

$\mathrm{Ph}=$ phenotypes

$P 1=$ plants

$\mathrm{Ra}=$ ramets

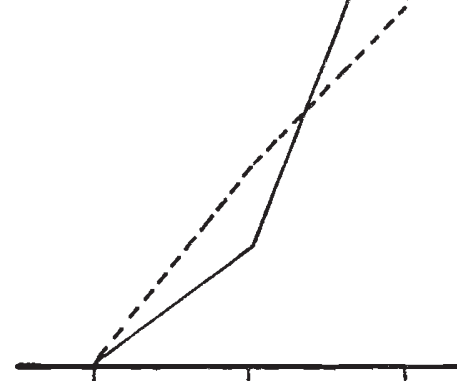

SERIES 2

ANGLESEY

$4(N=48: 4 \mathrm{Ph} \times 3 \mathrm{P} I \times 4 \mathrm{R} \mathrm{E})$

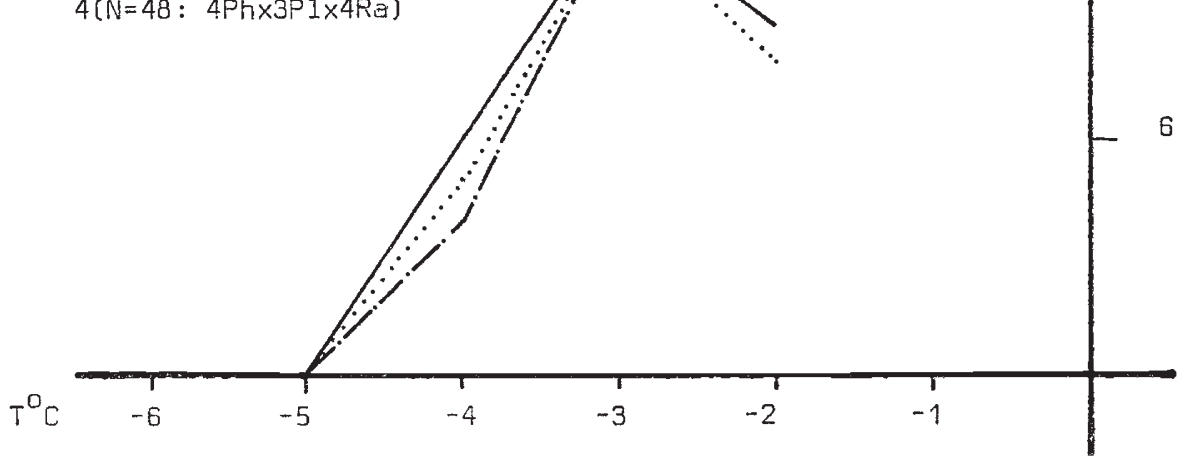

Fig. 1.-The numbers of each phenotype surviving are plotted against night temperature for the two series of cold stress experiments. In series 1, 24 plants each of two phenotypes, ++ and +- , were used and in series 2, 12 plants each of all four phenotypes were used. The same numbers of ++ and +- plants survived in each experiment of series 2 , so they are both plotted as a solid line. 
From these experiments we can conclude that $L$. corniculatus plants can tolerate temperatures as low as $-3^{\circ} \mathrm{C}$ for seven successive nights, suffering only reversible injury, if any, but that at lower temperatures irreversible injury and death occurs. It is the reversible injury which may discriminate between the phenotypes in terms of selective advantage. This type of frost stress may be due to freeze dehydration of the cells (Levitt, 1972) and it can be profitably compared to the drought stress work of Foulds and Grime (1972). In both instances the selective stress may act by causing physiological dehydration of cells, but the physiological disadvantage of cyanogenic plants remains undetermined. Perhaps discrimination between phenotypes could be improved by using competition experiments under frost stress, such as those of Deschênes (1974). He showed that the mortality of $L$. corniculatus increased with increased seeding rate and in response to weed competition. However, there is no good evidence to date that cold temperature acts as a selective agent in populations of $L$. corniculatus to maintain the polymorphism of cyanogenesis. The distribution of cyanogenic $L$. corniculatus in the Scottish Highlands and the French Alps (Jones, 1977) bears no relationship to altitude and hence with cold temperature, and the results obtained here show that cyanogenic plants are no more vulnerable to cold stress than acyanogenic plants.

\section{Conclusions}

Because some individuals in the Anglesey population can change their cyanogenic phenotype in response to changes of temperature, whereas others do not, a genotype $\times$ environment interaction occurs in that population. These effects of temperature may be related to the genetic structure of this and other populations. Our hypothesis is that stability of phenotypic expression is associated with homozygosity and higher-order heterozygosity, for example in the Wharram population, and instability with lower-order heterozygosity, for example in the Anglesey population.

This instability in heterozygotes may also explain why Dawson (1941) had anomalous results when working with English populations and consequently chose Scandinavian material for his breeding work on the inheritance of cyanogenesis. Perhaps the next step should be to determine the genotypes of stock plants, measure the phenotypic stability of artificial heterozygotes and assess the selective advantage of developmental flexibility in experimental populations. Further work is already in progress on assessing the frequency of unstable forms in different populations.

We have been unable to show that cold temperature stress differentiates between the cyanogenic and acyanogenic phenotypes. In this respect $L$. corniculatus differs from $\mathcal{T}$. repens, so that we still cannot nominate cold temperature as a selective agent acting directly on the polymorphism of cyanogenesis in $L$. corniculatus.

In terms of the demonstrated advantage of chemical defence (Ellis $e$ al., 1977a) flexibility which reduces the expression of the cyano-glucoside under cold conditions would not be deleterious: molluscs are notably inactive at low temperatures (Crawford-Sidebotham, 1972a).

Acknowledgments.-We are most grateful to the Science Research Council (B/RG/33539, W. M. E. and D. A. J.) and to the Natural Environment Research Council and to the Sir Philip Reckitt Educational Trust (research studentship, R. J. K.) for the financial support 
of this work, to Miss A. K. Braithwaite and Mr V. Swetez for their care of the glasshouse plants and temperature records and to Mr Macdonald at the Experimental Husbandry Farm, High Mowthorpe, for temperature data. We wish to thank the Management Committee of Wharram Quarry for permission to work at the quarry. We are grateful for the comments of the referees on an earlier draft of this paper.

\section{REFERENCES}

DE ARÁuJO, A. M. 1976. The relationship between altitude and cyanogenesis in white clover (Trifolium repens L.). Heredity, 37, 291-293.

ARMSTrong, H. E., ARMSTRONG, E. F., AND Horton, E. 1913. Herbage studies. II. Variation in Lotus corniculatus and Trifolium repens (cyanophoric plants). Proc. Roy. Soc. B, 86, 262-269.

Askew, H. O. 1933. Determination of hydrocyanic acid in white clover. N.Z.J. Sci. Tech., $15,227-233$.

ATWOOD, s. S., AND sullivan, J. T. 1943. Inheritance of a cyanogenetic glucoside and its hydrolysing enzyme in Trifolium repens. 7. Hered., 34, 311-320.

BANSAL, R. D. 1966. Studies on procedures for combining clones of Birdsfoot Trefoil, Lotus corniculatus L. Ph.D. Thesis, Cornell University.

BREESE, E. L., HAYWARD, M. D., AND THOMAS, A. C. 1965. Somatic selection in perennial ryegrass. Heredity, 20, 367-379.

CORKILL, L. 1942. Cyanogenesis in white clover (Trifolium repens L.). V. The inheritance of cyanogenesis. N.Z.J. Sci. Tech., 23, 178B-193B.

CRAWFORD-SIDEBOTHAM, T. J. 1972a. The influence of weather upon the activity of slugs. Oecologia, 9, 141-154.

CRAWFORD-SIDEBOTHAM, T. J. 1972b. The role of slugs and snails in the maintenance of the cyanogenesis polymorphisms of Lotus corniculatus and Trifolium repens. Heredity, 28, 405-411.

DADAY, H. 1954a. Gene frequencies in wild populations of Trifolium repens L. I. Distribution by latitude. Heredity, 8, 61-78.

DADAY, H. 1954b. Gene frequencies in wild populations of Trifolium repens L. II. Distribution by altitude. Heredity, 8, 377-384.

DADAY, H. 1965. Gene frequencies in wild populations of Trifolium repens L. IV. Mechanism of natural selection. Heredity, 20, 355-365.

DAWSON, C. D. R. 1941. Tetrasomic inheritance in Lotus corniculatus L. 7. Genetics, 42, 49-72.

DEschenes, J. M. 1974. Competitive effects of barnyard grass and corn spurry on yields of birdsfoot trefoil. Can. 7. Plant Sci., 54, 463-470.

ELLIS, W. M., KEYMER, R. J., AND JONES, D. A. 1977a. The defensive function of cyanogenesis in natural populations. Experientia, 33, 309-311.

ELLIS, w. M., KEYMER, R. J., AND JONES, D. A. 1977b. On the polymorphism of cyanogenesis in Lotus corniculatus L. VIII. Ecological studies in Anglesey. Heredity (in press).

FOUlDS, W., AND GRIME, J. P. 1972. The influence of soil moisture on the frequency of cyanogenic plants in populations of Trifolium repens and Lotus corniculatus. Heredity, 28, 143-146.

JONES, D. A. 1962. Studies on the polymorphism and antibody formation in lower organisms and their bearing on ecological genetics and human serology. D.Phil. Thesis, Oxford.

JONES, D. A. 1966. On the polymorphism of cyanogenesis in Lotus corniculatus L. I. Selection by animals. Can. 7. Genet. Cytol., 8, 556-567.

JONES, D. A. 1977. On the polymorphism of cyanogenesis in Lotus corniculatus L. VII. The distribution of the cyanogenic form in Western Europe. Heredity (in press).

LEVITT, J. 1972. Responses of plants to environmental stress. Academic Press, New York and London.

LIBBY, w. J., AND JUND, E. 1962. Variance associated with cloning. Heredity, 17, 533-540. OSTAZESKI, S. A., AND HENSON, P. R. 1965. Effect of morphology of propagules on performance of Birdsfoot Trefoil clones, Crop Sci., 5, 253-254.

USHer, м. в. 1975. Analysis of pattern in real and artificial plant populations. 7. Ecol., 63, 569-586.

DE WAAL, D. 1942. Het cyanophore karakter van witte klaver (Trifolium repens L.) Ph.D. Thesis, Wageningen.

WESTERMAN, J. M., AND LAWRENCE, M. J. 1970. Genotype-environment interaction and developmental regulation in Arabidopsis thaliana. 1. Inbred lines: description. Heredity, $25,609-627$. 